\title{
Retrospective Study of Reproductive Diseases of Small Ruminants in Northern Barind Tract in Bangladesh
}

\author{
Md. Hemayatul Islam', Md. Jalal Uddin Sarder, ", Md. Siddiqur Rahman ${ }^{3}$, Md. Ariful Haque ${ }^{2}$, \\ Md. Akhtarul Islam ${ }^{1}$, Syed Sarwar Jahan ${ }^{1}$, Rashida Khaton ${ }^{1}$ \\ ${ }^{1}$ Department of Animal Husbandry and Veterinary Science, University of Rajshahi, Bangladesh \\ ${ }^{2}$ Institute of Biological Sciences, University of Rajshahi, Rajshahi-6205, Bangladesh \\ ${ }^{3}$ Faculty of Veterinary science, Bangladesh Agricultural University, Mymensing, Bangladesh
}

\section{Email address:}

jalalnusa@yahoo.com (Md. J. U. Sarder)

\section{To cite this article:}

Md. Hemayatul Islam, Md. Jalal Uddin Sarder, Md. Siddiqur Rahman, Md. Ariful Haque, Md. Akhtarul Islam, Syed Sarwar Jahan, Rashida Khaton. Retrospective Study of Reproductive Diseases of Small Ruminants in Northern Barind Tract in Bangladesh. Animal and Veterinary Sciences. Vol. 3, No. 5, 2015, pp. 136-140. doi: 10.11648/j.avs.20150305.13

\begin{abstract}
Context: The information of diseases prevalence give useful information on disease pattern and thus can be used in preventing diseases as well as formulating policies for future management to prevent diseases. Aim: This study is therefore aimed at determining the pattern of reproductive diseases encountered at the Barind tract in Bangladesh. Materials and Method: The primary data were collected by randomly selected location in each district of retrospective survey from the veterinary and vaccination camp of the study area. Records of 2667 clinical cases of small ruminants (2394 goats, 273 sheep) questionnaires report under this study, from July 2012 to June 2013 were analyzed to assess the importance of existing diseases. The computer program SPSS were analyzed the study and Chi-square and F test were used for significance test. Results: The small ruminants were significantly suffering from various diseases and disorders. The maximum $816(30.6 \%)$ was affected by infectious diseases and lowest $18(0.7 \%)$ was affected with poisonous diseases in small ruminants. The others diseases highest to lowest rate were $444(16.6 \%), 354(13.3 \%), 345(12.9 \%), 231(8.7 \%), 162(6.1 \%), 102(3.8 \%), 84(3.1 \%), 72(2.7 \%)$ and $39(1.5 \%)$ affected with gastrointestinal, respiratory, surgical, female reproductive disorder, deficiency syndrome, Integumentary involvement, diseases of sense organ, musculoskeletal system and disease of male sex organ respectively in small . The highest disease prevalence $(89.8 \%)$ was observed in goat than in sheep (10.2\%) and the total reproductive disease prevalence was $10.2 \%$. The highest \& lowest incidence rates of reproductive disorders in relation to sex were $32.5 \% \& 1.9 \%$ in anoestrus and postitis. Similarly, the age had significant effect $(\mathrm{P}<0.05)$ and highest value were $20.4 \%, 7.9 \%$ \& $4.5 \%$ observed in anoestrus of young, adult and old ages respectively. The season had significant effect and the overall disease prevalence was higher rainy season $40.4 \%$, but the individual highest value observed in anoestrus $14.7 \%$ in winter season. Conclusion: The one tenth portion of disease prevalence got in reproductive related case, but most frequent reproductive diseases and disorder were in found in goat, female animal, young age, rainy season and particularly in anoestrus condition of small ruminants at northern Barind tract in Bangladesh.
\end{abstract}

Keywords: Reproductive Diseases, Prevalence, Age, Sex, Seasons

\section{Introduction}

The magnitude of contribution of the livestock sector to the GDP is $2.6 \%$ in Bangladesh and $80 \%$ rural people rear indigenous animals. The present population of goat and, sheep are 22400000 and 2870000 respectively [1] (DLS, 2010). The Barind tract is situated in the Northern belt of Bangladesh. The area of Barind area in particular is known to tilt a farther $15 \mathrm{M}$ upwards in the west. On the other hand Barind Tract has a different geographic character than other parts of Bangladesh.
Its soil formation is also different from others parts of Bangladesh. This northern part is 37 meter above sea level. People in this area used to cultivate rice once a year, but now produce various crops such as rice, white and pulses round the year. The other time of the year left that is suitable for grazing of animal especially small ruminants [2](Alice Mbugua 2011). Livestock sector provides full time employment to approximately $20 \%$ and part time employment to 
approximately $50 \%$ of the rural population of Bangladesh. It also generates an adequate amount of foreign currency every year by exporting hides and skin and their products. Besides, per capita income of Bangladesh is 750 US dollar and $49 \%$ of the total population of Bangladesh is malnourished. Per capita requirement of protein cannot be fulfilled by our protein sources. So, continuous protein deficiency causes various nutritional deficiency diseases followed by infectious diseases and reproductive disturbances. If the livestock sector develops, it will be able to fulfill the existing requirement of protein for the country. Disease is defined as inability to perform physiological functions at normal levels even though nutrition and other environmental requirements are provided at adequate levels [3] (Radositis et al., 2007). Disease conditions always impair livestock production [4-5] (Akerejola etal, 1979; Lamorde, 1996). Apart from this, several other factors such as environment and nutrition, especially inadequate protein intake [6-7] (Kumidiake et al., 1981; Smith and Somade, 1994) decrease reproductive performance. However, technological difficulties in these countries hinder extensive use of modern diagnostic techniques in disease surveillance [8] (Nwanta et al., 2000). Diseases and climatic problems have been blamed as the main limitation to modern animal husbandry in tropical areas [9] (Loosli et al., 1974). It is therefore important to understand not only the interactions between different diseases occurring in the same environment, but also the modulating influence of the climatic factors driving the seasonal variations usually observed [10](Onwuliri et al 1993). Such knowledge is essential in planning control strategies against reproductive diseases. Approximately $36 \%$ protein requirement is fulfilled by livestock sector. In the rural area of Plain land of Bangladesh livestock rearing such as beef fattening, goat rearing, buck rearing and sheep rearing are gradually increasing day by day. Small ruminants are allowed to roam throughout the seasons, thriving on indigenous browses growing in compound bushes and farm fallows with additional supplementation from kitchen wastes [11] (Okoli et al. 2003). The goat is called the "Poor man's cow" is the second important livestock in Bangladesh which plays an important role in the rural economy and earn substantial amount of foreign currency by exporting skin and others by products [12] (Kamaruddin, 2003). Each year goat production provides 127,000 MT meats, which accounts for $25 \%$ of total red meat in Bangladesh [13](FAO, 2007). Even in urban area goats and sheep are being raised under an intensive system of management by stall feeding with bran, fodder and tree leaves. So there is a lot of prospect to rear small ruminants in that area and Several reports have been written on livestock diseases in the country, but with very little attention to small ruminant's diseases especially reproductive diseases. These studies are usually emphasis to analysis the prevalence rate and evaluation of sex, age and seasonal influence on reproductive disease trends in small ruminants.

\section{Materials and Methods}

\subsection{Sources of Information}

The primary data were collected by randomly selected location in each district of retrospective survey from the veterinary and vaccination camp of the study area. The Health and Vaccination awareness camp was taken by primary questionnaire were filled up. The vaccination camps were in Nachal Upazilla Livestock office Chapainowabjong; Youth training centre, Noagoan; Moukhara High school field, Natore and Parila Primary School field, Paba, Rajshahi. The other data were collected from data record book of Veterinary Clinic and Artificial Insemination Center in the Department of Animal Husbandry and Veterinary Science, University of Rajshahi. Records of 2667 clinical cases of small ruminant (2394 goats, 273 sheep) questionnaires report under this study, from July 2012 to June 2013 were analyzed to assess the importance of existing diseases. The results were analyzed into eleven major diagnostic groups in small ruminants. The age of each animal was determined by asking the owner and by dentition. Diagnosis of these cases was made on the basis of signalment (age, sex and breed), clinical history and clinical examinations. To avoid overlapping of these diseases, certain adjustments were made so that each disease was counted under only one group. The data on the occurrence of clinical diseases and disorders were analyzed into eleven major diagnostic groups.

\subsection{Data Processing}

These groups were: (1) Gastro intestinal system involvement, (2) Respiratory system involvement (3) Musculoscletal system involvement, (4) Integumentary involvement, (5) Diseases of senses organ, (6) Infectious diseases (includes PPR, rabies, tetanus Naval ill, pregnancy toxemia, worm infestation and coccidiosis) (7) Deficiency and metabolic diseases, (8) Poisonous diseases, (9) Common Surgery, (10) Female reproductive diseases and (11) Male sex organ involvement. The age sex and seasonal influence on the occurrence of diseases were also analyzed. Accordingly, data were analyzed into three age groups: Kids/ lambs (below 12 months) adults (12 to 24 months) and older (more than 24 months) aged. Sex was male and female and. We considered three seasons as summer from March to May, Rainy from June to October and winter from November to February. The small ruminants' diseases of male and female reproductive involvement were selection for further revision. Data on clinical cases of reproductive abnormalities (in case of female) were abortion, anoestrus, cervicitis, dystocia, endometritis, pyometra, repeat breeding, retained placenta, still birth and vaginal or uterine prolapsed as well as in male it is orchitis, postitis, and urinary tract infection. Diagnoses at the health and vaccination campaign by the veterinarian were usually based on flock history, clinical sign and symptoms.

\subsection{Statistical Analysis}

Data were statistically analyzed by Statistical Package for 
Social Science (SPSS) software 17.0 version [14]. Chi-square and $\mathrm{F}$ test was used to know the association between different groups in respective cases.

\section{Results}

The diseases and reproductive disorders observed in the different systems of small ruminants are shown in the Table 1-4. A total 2667 cases were presented to the study, and of these, $270(10.2 \%)$ were reproductive case. The percentage distribution of diseases according to species shows goat with the highest number of cases 2394 (89.8\%), then sheep 273 $(10.2 \%)$ (Table1). In the study it was found that small ruminant were significantly suffering from various diseases and disorders, where maximum $816(30.6 \%)$ of small ruminants were affected by infectious diseases. The lowest number $18(0.7 \%)$ small ruminants affected with poisonous diseases. The other number of diseases involve in small were highest to lowest rate $444(16.6 \%), 354(13.3 \%), 345(12.9 \%)$, $231(8.7 \%), 162(6.1 \%), 102(3.8 \%), 84(3.1 \%), 72(2.7 \%)$ and $39(1.5 \%)$ were in gastrointestinal, respiratory, surgical, female reproductive disorder, deficiency syndrome, Integumentary involvement, diseases of sense organ, musculoskeletal system and disease of male sex organ, respectively. The overall incidence rate of reproductive disorder was 10.2 , where $8.7 \%$ in female and $1.5 \%$ in male sex involvement. The incidence rate (highest to lowest) of reproductive disorders involvement with relation to sex were $32.8 \%, 15.8 \%, 10.2 \%, 7.9 \%, 6.8 \%, 5.7 \%, 4.5 \%$ in anoestrus, abortion, dystocia, retained placenta, cervicities, mastitis and repeat breeding in case of female, but in male it was $5.7 \%$, $5.3 \%, 2.6$ and $1.9 \%$ in urinary tract infection, urolithiasis, postitis and orchitis, respectively (table 2). The study also revealed that the reproductive disorders of small ruminants were varied with aged. The incidence rate of cervicities, abortion, mastitis, retained placenta, anoestrus, repeat breeding, dystocia, urinary tract infection, postitis, urolithiasis and orchitis were $5.7 \%, 8.7 \%, 2.3 \%, 5.7 \%, 20.4 \%, 1.1 \%$, $4.5 \%, 4.2 \%, 1.9 \%, 1.9 \%$ \& $1.9 \%$ in young; $1.1 \%, 5.7 \%, 2.3 \%$, $2.3 \%, 7.9 \%, 2.3 \%, 1.1 \%, 1.5 \%, 0 \%, 3.4 \% \& 0.8 \%$ and in adult $0 \%, 1.5 \%, 1.1 \%, 2.3 \%, 4.5 \%, 1.1 \%, 2.3 \%, 0.8 \%, 0 \%, 0 \% \& 0 \%$ in older respectively (table 3 ). The seasonal influence also diverse with the reproductive disorders of small in case of cervicities, abortion, mastitis, retained placenta, anoestrus, repeat breeding, dystocia, urinary tract infection, postitis, urolithiasis and orchitis were $1.1 \%, 3.4 \%, 3.4 \%, 1.1 \%, 9.1 \%$, $0.0 \%, 2.3 \%, 2.3 \%, 0.8 \%, 1.9 \%$ \& $1.9 \%$ in summer; $3.4 \%$, $6.8 \%, 2.3 \%, 6.8 \%, 9.1 \%, 1.1 \%, 5.7 \%, 2.6 \%, 1.1 \%, 1.5 \%$ \& $0.0 \%$ in rainy and $2.3 \%, 5.7 \%, 0 \%, 2.3 \%, 14.7 \%, 3.4 \%, 0 \%$, $1.5 \%, 0 \%, 1.9 \% \& 0.8 \%$ in winter respectively (table 4 ).

\section{Discussion}

The retrospective study provided preliminary information on the incidence and pattern of the reproductive disorder prevalent at the Northern Barind tract in Bangladesh. The frequency of reproductive disorder randomly distributed among the species. However, there were more cases affecting small (goat and sheep). This can be explained since small ruminants are in absolute terms, more numerous and it is relatively cheaper to rear small ruminants within the Barind area (Urban area) where they are simply allowed to roam freely and scavenge for food. The occurrence of diseases was predominate to be more in female than male [15] (Wazari et al., 2006) due to the presence of higher number of female animals in the study area [16](Ali et al 2011). This is consistent with the fact that females are kept for longer periods in the herd for breeding or milk supply than the males. Also, the peculiarity of the female's vulnerability could be a contributing factor and observed high frequency of anoestrus. The relationship between nutritional / management factors, poor feeding and present in infectious agent in the environment would be the second position of abortion. Twining poor feeding and management as a cause of dystocia [17-20](Arthur et al., 1998; Dryendahl et al., 1977; Bendixen et al., 1987 \& Islam et al., 2013) may be associated with the relatively high incidence of dystocia and retained placenta observed in the study. Similarly the high incidence of urinary tract infection in male would be associated with service to any types of small ruminants, dry weather of the region and neglected of the infection.

Similarly the general frequency of the disease was randomly distributed throughout the year, but relatively more cases were encountered during the month of July to October (rainy season) followed by month of November to February (winter season) than the month of March to June (dry or summer season) which partially agree with Khair et al. [21] (2013) and disagree with Waziri et al.[15] (2006) The rainy season lies highest frequency may be due to the lack or scarcity of fodder and lack of grazing.

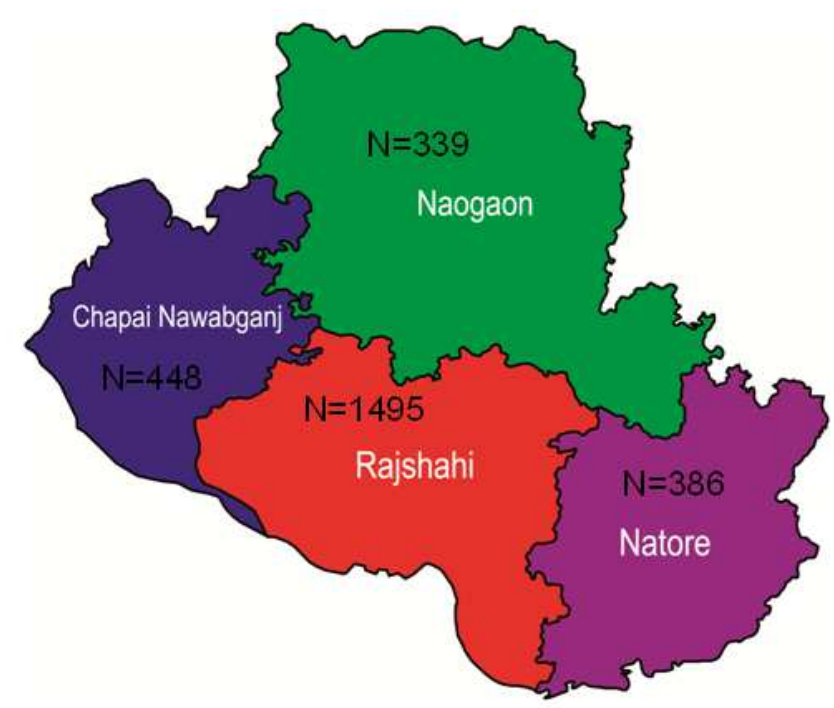

Figure 1. Area of sample collection at Northern Barind Tract in Bangladesh. 
Table 1. Distribution of diseases of small ruminants.

\begin{tabular}{|c|c|c|c|}
\hline \multirow{2}{*}{ Diseases } & \multicolumn{2}{|c|}{ Small ruminants } & \multirow{2}{*}{ Total } \\
\hline & Goat & Sheep & \\
\hline Gastrointestinal & $372(13.9 \%)$ & $72(2.7 \%)$ & $444(16.6 \%)$ \\
\hline Respiratory & $327(12.3 \%)$ & $27(1.0 \%)$ & $354(13.3 \%)$ \\
\hline Musculoskeletal system & $69(2.6 \%)$ & $3(0.1 \%)$ & $72(2.7 \%)$ \\
\hline Female reproductive & $183(6.9 \%)$ & $48(1.8 \%)$ & $231(8.7 \%)$ \\
\hline Integumentary involvement & $93(3.5 \%)$ & $9(0.3 \%)$ & $102(3.8 \%)$ \\
\hline Disease of Sense organ & $78(2.9 \%)$ & $6(0.2 \%)$ & $84(3.1 \%)$ \\
\hline Deficiency syndrome & $153(5.7 \%)$ & $9(0.3 \%)$ & $162(6.1 \%)$ \\
\hline Poison & $12(0.4 \%)$ & $6(0.2 \%)$ & $18(0.7 \%)$ \\
\hline Male sex organ & $39(1.5 \%)$ & $0(0 \%)$ & $39(1.5 \%)$ \\
\hline surgical & $318(11.9 \%)$ & $27(1.0 \%)$ & $345(12.9 \%)$ \\
\hline Total & $2394(89.8 \%)$ & $273(10.2 \%)$ & $2667(100 \%)$ \\
\hline F value & 7.882 & Significant & \\
\hline
\end{tabular}

Table 2. Distribution of reproductive diseases of small ruminants associated with sex.

\begin{tabular}{llll}
\hline \multirow{2}{*}{ Legend } & \multicolumn{3}{c}{ Sex of small ruminants } \\
\cline { 2 - 4 } & Male & Female & $18(6.8 \%)$ \\
\hline Cervicities & - & $18(6.8 \%)$ & $42(15.8 \%)$ \\
Abortion & - & $42(15.8 \%)$ & $15(5.7 \%)$ \\
Mastitis & - & $15(5.7 \%)$ & $27(10.2 \%)$ \\
Retained placenta & - & $27(10.2 \%)$ & $87(32.8 \%)$ \\
Anoestrus & - & $87(32.8 \%)$ & $12(4.5 \%)$ \\
Repeat breeding & - & $12(4.5 \%)$ & $21(7.9 \%)$ \\
Dystocia & - & $21(7.9 \%)$ & $17(6.4 \%)$ \\
Urinary tract Infection & $15(5.7 \%)$ & $2(0.8 \%)$ & $5(1.9 \%)$ \\
Postitis & $5(1.9 \%)$ & - & $14(5.3 \%)$ \\
Urolithiasis & $14(5.3 \%)$ & - & $7(2.6 \%)$ \\
Orchitis & $7(2.6 \%)$ & - & $265(100 \%)$ \\
Total & $41(15.5 \%)$ & $224(84.5 \%)$ & Significant P<0.05 \\
Chi-Square Test & Calculated value & Tabulated value & \\
\hline
\end{tabular}

Table 3. Distribution of reproductive diseases of small ruminants associated with age.

\begin{tabular}{|c|c|c|c|c|}
\hline \multirow{2}{*}{ Legend } & \multicolumn{3}{|c|}{ Age of the small ruminants } & \multirow{2}{*}{ Total } \\
\hline & Young $0<12$ Months & Adult $12<24$ Months & Old $>24$ Months & \\
\hline Cervicities & $15(5.7 \%)$ & $3(1.1 \%)$ & $0(0 \%)$ & $18(6.8 \%)$ \\
\hline Abortion & $23(8.7 \%)$ & $15(5.7 \%)$ & $4(1.5 \%)$ & $42(15.8 \%)$ \\
\hline Mastitis & $6(2.3 \%)$ & $6(2.3 \%)$ & $3(1.1 \%)$ & $15(5.7 \%)$ \\
\hline Retained placenta & $15(5.7 \%)$ & $6(2.3 \%)$ & $6(2.3 \%)$ & $27(10.2 \%)$ \\
\hline Anoestrus & $54(20.4 \%)$ & $21(7.9 \%)$ & $12(4.5 \%)$ & $87(32.8 \%)$ \\
\hline Repeat breeding & $3(1.1 \%)$ & $6(2.3 \%)$ & $3(1.1 \%)$ & $12(4.5 \%)$ \\
\hline Dystocia & $12(4.5 \%)$ & $3(1.1 \%)$ & $6(2.3 \%)$ & $21(7.9 \%)$ \\
\hline Urinary tract Infection & $11(4.2 \%)$ & $4(1.5 \%)$ & $02(0.8 \%)$ & $17(6.4 \%)$ \\
\hline Postitis & $5(1.9 \%)$ & $0(0 \%)$ & $0(0 \%)$ & $5(1.9 \%)$ \\
\hline Urolithiasis & $5(1.9 \%)$ & $9(3.4 \%)$ & $0(0 \%)$ & $14(5.3 \%)$ \\
\hline Orchitis & $5(1.9 \%)$ & $02(0.8 \%)$ & $0(0 \%)$ & $7(2.6 \%)$ \\
\hline Total & $154(58.1 \%)$ & $75(28.3 \%)$ & $36(13.6 \%)$ & $265(100 \%)$ \\
\hline Chi-Square Test & $\begin{array}{l}\text { Calculated value } \\
36.279\end{array}$ & $\begin{array}{l}\text { Tabulated value } \\
31.410\end{array}$ & Not Significance $\mathrm{P}>0.05$ & \\
\hline
\end{tabular}

Table 4. Distribution of reproductive diseases of small ruminants associated with Season.

\begin{tabular}{llll}
\hline \multirow{2}{*}{ Legend } & \multicolumn{2}{c}{ Seasons of the Year } \\
\cline { 2 - 4 } & Summer (March to June) & Rainy (July to October) & Winter (November to February). \\
\hline Cervicities & $3(1.1 \%)$ & $9(3.4 \%)$ & $6(2.3 \%)$ \\
Abortion & $9(3.4 \%)$ & $18(6.8 \%)$ & $15(5.7 \%)$ \\
Mastitis & $9(3.4 \%)$ & $6(2.3 \%)$ & $0(0 \%)$ \\
Retained placenta & $3(1.1 \%)$ & $18(6.8 \%)$ & $6(2.3 \%)$ \\
Anoestrus & $24(9.1 \%)$ & $24(9.1 \%)$ & $39(14.7 \%)$ \\
Repeat breeding & $0(0.0 \%)$ & $3(1.1 \%)$ & $9(3.4 \%)$ \\
Dystocia & $6(2.3 \%)$ & $15(5.7 \%)$ & $0(0 \%)$ \\
Urinary tract Infection & $6(2.3 \%)$ & $7(2.6 \%)$ & $4(1.5 \%)$ \\
Postitis & $2(0.8 \%)$ & $3(1.1 \%)$ & $07 \%)$ \\
\end{tabular}




\begin{tabular}{lllll}
\hline \multirow{2}{*}{ Legend } & \multicolumn{3}{c}{ Seasons of the Year } & \multirow{2}{*}{ Total } \\
\cline { 2 - 4 } & Summer (March to June) & Rainy (July to October) & Winter (November to February). & $14(5.3 \%)$ \\
\hline Urolithiasis & $5(1.9 \%)$ & $4(1.5 \%)$ & $5(1.9 \%)$ & $7(2.6 \%)$ \\
Orchitis & $5(1.9 \%)$ & $0(0 \%)$ & $2(0.8 \%)$ & $265(100 \%)$ \\
Total & $72(27.2 \%)$ & $107(40.4 \%)$ & $86(32.5 \%)$ & \\
Chi-Square Test & Calculated value & Tabulated value & Significant P<0.05 & \\
\hline
\end{tabular}

\section{Acknowledgements}

We appreciate the assistance provided by farmer and the members of Bangladesh Livestock Society (BLS) to arrange the Veterinary Health and Vaccination Camp in data collection.

\section{Authors' Contributions}

Md. Hemayatul Islam designed the study, performed the data analysis and wrote the manuscript. Sarder MJU was supervised and contributed in development and pre-testing of the study questionnaire, data collection and reviewed the manuscript. The other authors read and approved the final manuscript.

\section{References}

[1] DLS (2010). Personal communication With Project Director, Animal Health Care, Management and Expansion Project, DLS, Dhaka.

[2] Alice Mbugua (2011) Research Report on Water Scarcity in Northern Bangladesh International volunteer, VSO and GBK staff, Parbatipur, Dinajpur: 1-25.

[3] Radostitis OM, Gay CC, Blood DC and Hinchcliff KW (2007) Veterinary Medicine. A Text book of the diseases of cattle, sheep, pig and horse, Ninth Edition, Bailliere Tindal, London, 1308 .

[4] Akerejola OC, Schillhorn VT, Njoku CO (1979) Ovine and Caprine diseases in Nigeria. Bulletin of Animal Health and Production in Africa 27: $65-68$.

[5] Lamorde AG (1996) The role of veterinarians on a developing economy. Nigerian Veterinary Journal (special edition) 1(1): $106-111$

[6] Kumidiaka J, Osori DIK., Ogwu D (1981) Incidence of genital abnormalities and physiological effect of genital pathology in indigenous cows. Nigerian Veterinary Journal 9: 52 - 54.

[7] Smith OS and Somade B (1994) Interaction between nutrition and reproduction in farm animals. IFS (International Foundation for science) Proceedings of a Regional Seminar on Animal Reproduction

[8] Nwanta JA, Hassan MI, and Alli-Balogun JK (2000) Epidemiology of PPR in northern states of Nigeria-An update. Proceedings25th Nigeria Society of Animal Production Annual Conference 19-23rd March 2000, Umudike, Nigeria.

[9] Maynard LA, and LOOSI JK (1969) Animal nutrition, 6th ed.
McGraw-Hill Book Co., New York. 613pp.

[10] Onwuliri COE, Anosike JC, Nkem CN and Payne U K (1993) The ecology of animal parasitic nematodes in endemic areas of Jos, Nigeria. Applied Parasitology 34: 131-137

[11] Okoli IC, Ebere CS, Uchegbu MC, Udah CA, Ibeawuchi II (2003) A survey of the diversity of plants utilized for small ruminant feeding in south-eastern Nigeria. Agriculture Ecosystems \& Environment 96 (1-3): 147-154.

[12] Kamaruddin KM (2003). Goat farming as a means of poverty alleviation. Proceeding of the BSVER symposium, Goats farming in Bangladesh; Problems and prospects. BAU. Bangladesh society for veterinary education research, BSVER Pub. No. 25 P- 26-34.

[13] FAO (2007). FAO production Year Book, Food and Agricultural organization of the USA, Rome, Italy. Vol 51.

[14] SPSS Inc. Released 2008. SPSS Statistics for Windows, Version 17.0. Chicago: SPSS Inc.

[15] Waziri MA, Adamu A and Bukar MM (2006) Analysis of Reproductive cases handeled at the state veterinary clinic Maidugure, Negeria. Negerian Veterinary Journal 27(2): 54-59.

[16] Ali MH, Bhuiyan MKJ and Alam MM (2011) Retrospective epidemiologic study of diseases in in Khagrachari hill tract District of Bangladesh. Bangladesh Veterinary Journal 11(1): 145-153.

[17] Arthur GH, Noakes DE, Pearson H, Parkinson TJ (1998) Veterinary Eproduction and Obstetrics, 7th Edition WB Saunders Co., Philadelphia: 185- 302.

[18] Dryendahl L, Mattson J and Peherson B (1977) Retained Placenta in cattle incidence, clinical data and effects on Postpartum release of fertility. Journal of the American Veterinary Medical Association 24: 529-541.

[19] Bendixen PH, Vilson B, and Ekesbo I (1987) Disease frequencies in dairy cows in Sweden. II. Retained Placenta. Preventative Veterinary Medicine 4:377-387.

[20] Islam MdH, Sarder MdJU, Jahan SS, Rahman M, Zahan M, Kader MdA and Mozaffor Hossain KM (2013) Retained placenta of dairy cows associated with managemental factors in Rajshahi, Bangladesh. Vet World 6(4):180-184, doi: 10.5455/vetworld.2013.180-184.

[21] Khairl MM, Alam1 AKMA, Rahman1 MT, Islam1 A, Azim and Chowdhury EH (2013) Incidence of reproductive and production diseases of cross-breed dairy cattle in Bangladesh. Bangl. J. Vet. Med. 11 (1): 31-36. 